\title{
Corrigendum
}

\section{Corrigendum to "Study of Modern Nano Enhanced Techniques for Removal of Dyes and Metals"}

\section{Journal of Nanomaterials}

Received 28 January 2019; Accepted 11 February 2019; Published 5 May 2019

Copyright ( 2019 Journal of Nanomaterials. This is an open access article distributed under the Creative Commons Attribution License, which permits unrestricted use, distribution, and reproduction in any medium, provided the original work is properly cited.

In the article titled "Study of Modern Nano Enhanced Techniques for Removal of Dyes and Metals" [1], the figures except Figure 1 were reused from other published articles. They were cited, but reuse was not explicitly indicated in the text or figure legends. In addition, the article was found to contain text from published work, some without citation.

The sources for the figures are as follows:

Figures 2, 3, and 4 from Cao et al. (2011) [2] (cited as reference 58), Figure 5 from Han et al. (2013) [3] (cited as reference 62), Figures 6, 7, and 8 from Johnson et al. (2013) [4] (cited as reference 29), Figures 9, 10, and 11 from Peng et al. (2010) [5] (cited as reference 109), Figures 12 and 13 from Niu et al. (2005) [6] (cited as reference 97), and Figures 14 and 15 from Antonopoulou et al. (2012) [7] (cited as reference 38).

The text in the Introduction, subsections 2.1, 3, 3.1, and 3.2, and the Conclusion was from the following articles:

(i) X. Cao, L. Ma, Y. Liang, B. Gao, and W. Harris, "Simultaneous immobilization of lead and atrazine in contaminated soils using dairy-manure biochar," Environmental Science \& Technology, vol. 45, no. 11, pp. 4884-4889, 2011 [2] (cited as reference 58)

(ii) Piao Xu, Guang Ming Zeng, Dan Lian Huang, Chong Ling Feng, Shuang Hu, Mei Hua Zhao, Cui
Lai, Zhen Wei, Chao Huang, Geng Xin Xie, and Zhi Feng Liu, "Use of iron oxide nanomaterials in wastewater treatment: a review," Science of The Total Environment, volume 424, 1 May 2012, pages 1-10, https://doi.org/10.1016/j.scitotenv.2012.02.023 [8] (not cited)

(iii) Josephraj Vijayaraghavan, S. J. Sardhar Basha, and Joe Jegan, "A review on efficacious methods to decolorize reactive azo dye," Journal of Urban and Environmental Engineering, v.7, n.1, p.30-47. doi: 10.4090/juee.2013.v7n1.030047 [9] (not cited)

(iv) Vesna V. Panić, Sanja I. Šešlija, Aleksandra R. Nešić, and Sava J. Veličković, "Classification of azo dyes: adsorption of azo dyes on polymer materials," Hem. Ind. 67 (6) 881-900 (2013) doi: 10.2298/ HEMIND121203020P [10] (not cited)

(v) Ashley Johnson, Giorvanni Merilis, Jason Hastings, M. Elizabeth Palmer, Jeffrey P. Fitts, and Dev Chidambaram, "Reductive degradation of organic compounds using microbial nanotechnology," J. Electrochem. Soc. 2013 160(1): G27-G31. doi: 10.1149/2.053301jes [4] (cited as reference 29)

The editorial board approved this corrigendum, but the corresponding author did not. 


\section{References}

[1] S. Batool, S. Akib, M. Ahmad, K. S. Balkhair, and M. A. Ashraf, "Study of modern nano enhanced techniques for removal of dyes and metals," Journal of Nanomaterials, vol. 2014, Article ID 864914, 20 pages, 2014.

[2] X. Cao, L. Ma, Y. Liang, B. Gao, and W. Harris, "Simultaneous immobilization of lead and atrazine in contaminated soils using dairy-manure biochar," Environmental Science \& Technology, vol. 45, no. 11, pp. 4884-4889, 2011.

[3] X. Han, C. F. Liang, T. Q. Li, K. Wang, H. G. Huang, and X. E. Yang, "Simultaneous removal of cadmium and sulfamethoxazole from aqueous solution by rice straw biochar," Journal of Zhejiang University Science B, vol. 14, no. 7, pp. 640-649, 2013.

[4] A. Johnson, G. Merilis, J. Hastings, M. Elizabeth Palmer, J. P. Fitts, and D. Chidambaram, "Reductive degradation of organic compounds using microbial nanotechnology," Journal of the Electrochemical Society, vol. 160, no. 1, pp. G27-G31, 2013.

[5] Q. Peng, Y. Liu, G. Zeng, W. Xu, C. Yang, and J. Zhang, "Biosorption of copper(II) by immobilizing Saccharomyces cerevisiae on the surface of chitosan-coated magnetic nanoparticles from aqueous solution," Journal of Hazardous Materials, vol. 177, no. 1-3, pp. 676-682, 2010.

[6] S.-F. Niu, Y. Liu, X. H. Xu, and Z. H. Lou, "Removal of hexavalent chromium from aqueous solution by iron nanoparticles," Journal of Zhejiang University Science, vol. 6B, no. 10, pp. 1022-1027, 2005.

[7] M. Antonopoulou, A. Giannakas, and I. Konstantinou, "Simultaneous photocatalytic reduction of $\mathrm{Cr}(\mathrm{VI})$ and oxidation of benzoic acid in aqueous N-F-Codoped $\mathrm{TiO}_{2}$ suspensions: optimization and modeling using the response surface methodology," International Journal of Photoenergy, vol. 2012, Article ID 520123, 10 pages, 2012.

[8] P. Xu, G. M. Zeng, D. L. Huang et al., "Use of iron oxide nanomaterials in wastewater treatment: a review," Science of the Total Environment, vol. 424, pp. 1-10, 2012.

[9] J. Vijayaraghavan, S. J. Sardhar Basha, and J. Jegan, "A review on efficacious methods to decolorize reactive azo dye," Journal of Urban and Environmental Engineering, vol. 7, no. 1, pp. 030-047, 2013.

[10] V. V. Panić, S. Šešlija, A. Nešić, and S. Veličković, “Adsorption of azo dyes on polymer materials," Hemijska Industrija, vol. 67, no. 6, pp. 881-900, 2013. 


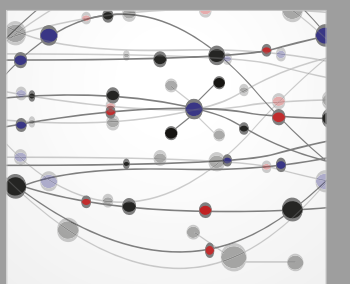

The Scientific World Journal
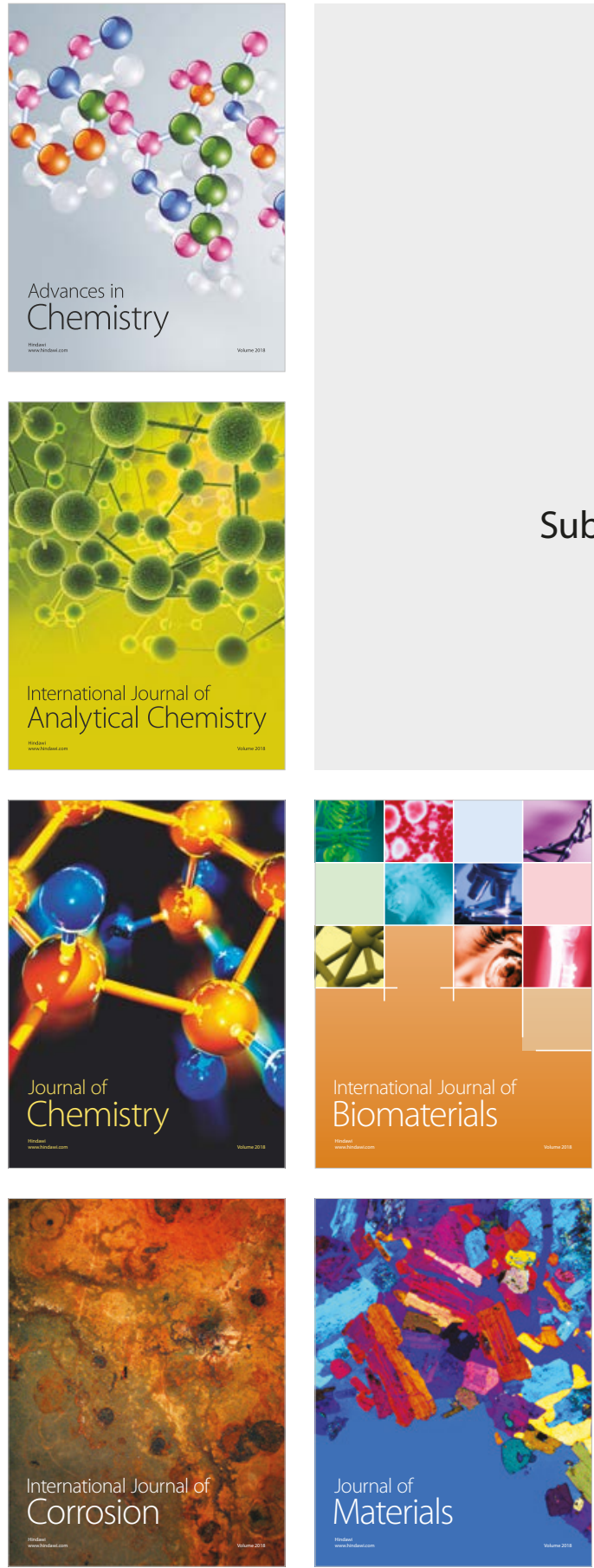

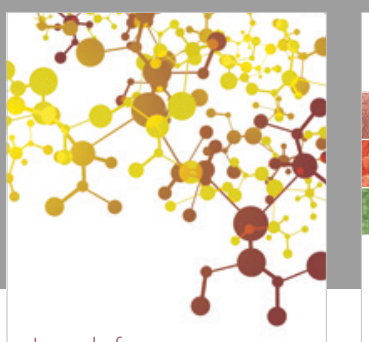

Journal of

Applied Chemistry
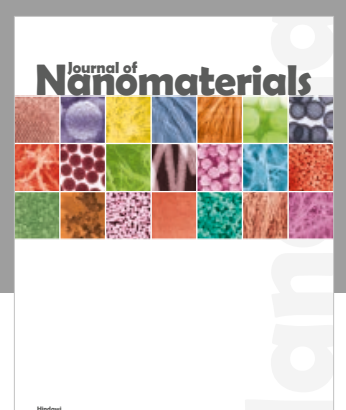

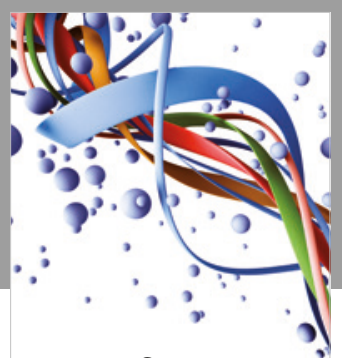

Scientifica

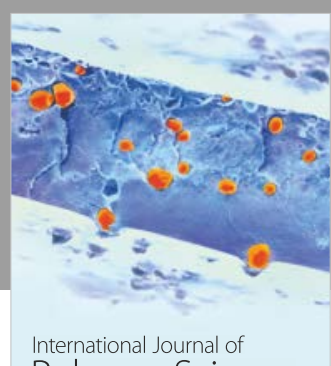

Polymer Science

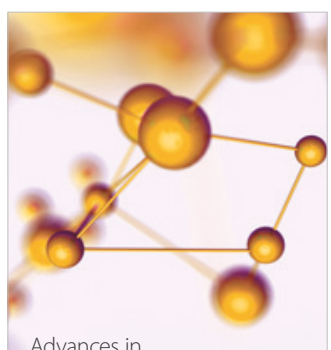

Physical Chemistry
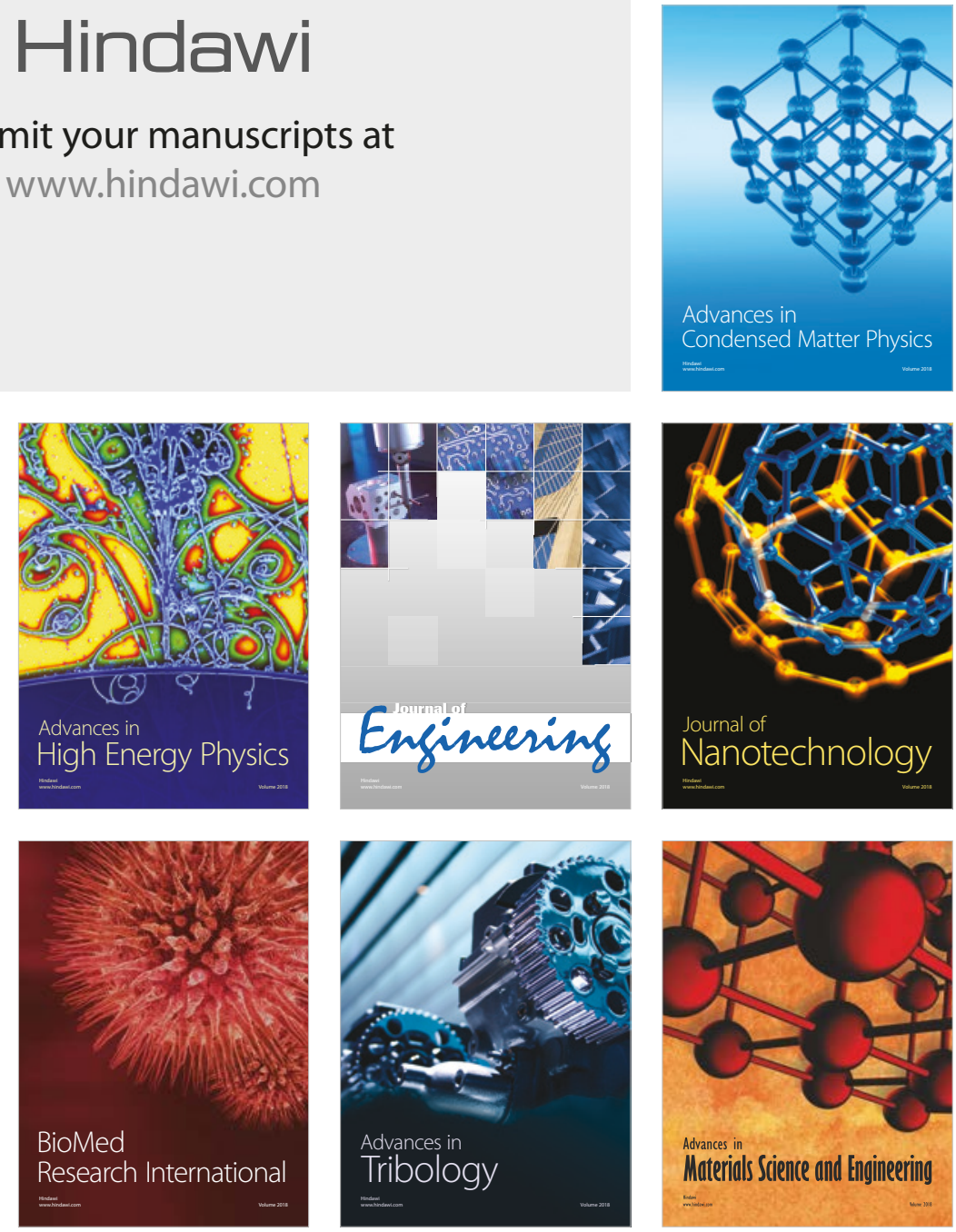